\title{
The burden of malaria: understanding the balance between immunity, public health and control
}

Throughout the last century, each wave of international interest in the control of malaria has highlighted its human and economic costs and their impact upon a country's development. During the 1920s, foreign support for malaria control in Africa was garnered through the serious economic threat to output and colonial development posed by the disease $[1,2]$. Underpinning the recent wave of international interest in malaria control is a continued reference to the economic burden malaria presents to development. Such considerations attract the involvement of key international partners who support economic reform and the alleviation of poverty $[3,4]$. The economics of health has evolved into a powerful political lobbying tool [5] as well as providing a scientific basis to identify cost-effective 'health buys' [6]. Nevertheless, efforts to apply a monetary value to malaria have occurred against a remarkably slow evolution in our understanding of the precise human costs posed by the Plasmodium falciparum parasite. Some may find it ironic that we can predict what proportion of GDP is lost through malaria while we remain relatively ignorant of the morbid and fatal risks an individual faces if exposed to the malaria parasite.

It has long been recognised that the relationships between P. falciparum infection, morbidity and disease outcome are complex. What we do know is that individuals born into areas of stable $P$. falciparum transmission frequently move between periods of being infected and remaining uninfected. Most individuals will, at some stage in their lives, develop an overt clinical response to an infection, often manifested as a febrile event associated with difficulties in breathing, diarrhoea and vomiting. A comparatively small proportion of these clinical events may progress to severe pathological clinical states, including acidosis, anaemia and altered consciousness. These may resolve naturally or the patient may survive through medical intervention. However, even with optimal clinical management, case fatality rates for conditions such as cerebral malaria are often in excess of $15 \%$ [7]. It has been estimated that c. 1 million people die each year in Africa from the direct consequences of P. falciparum infection [7].

The comparative risks of infection, mild morbidity, severe complicated disease and mortality during child- hood have been recorded during a series of studies at Kilifi, on the Kenyan Coast. The study population comprised children aged $0-15$ years who could expect to receive about 10 new infections each year from the local vectors. The risks of severe malaria warranting admission to hospital and malaria deaths declined during early childhood ( $<5$ years), while the frequency of mild, clinical attacks fell some time later. As the risk of infection remained constant throughout childhood, it is reasonable to assume that these age-related findings are associated with the development of functional immunity. It appears that at least three levels of immune acquisition occur: initial protection against severe and fatal outcomes, followed by protection against mild, self-limiting clinical disease; much later, during adulthood, individuals develop an ability to regulate peripheral infection.

What is important for disease control is whether the cumulative risks of disease or death decline with declining parasite exposure. Clearly, at one end of the transmission spectrum where the risk of infection is very low, there will be a very slow acquisition of immunity and all age groups are likely to be at risk of both disease and death following infection. Under these conditions the relative risk of a particular disease outcome will simply be a function of the chance encounters with the parasite. Among communities experiencing a wide range of stable, moderate-to-high intensity transmission conditions, early acquisition of functional immunity becomes important. Recent studies in Africa among children admitted to hospital with severe, life-threatening disease show a marked decline in severe infection with increasing age in areas in which the local prevalence of asymptomatic infection is $>70 \%$. In areas with a local prevalence $<30 \%$, malaria occurs with similar frequency throughout childhood [8-13]. These observations support the view that the development of functional immunity may depend upon an ill-defined amount of parasite exposure from birth. Moreover, severe malarial anaemia tends to dominate the clinical picture in areas of high transmission, while cerebral malaria assumes increasingly greater importance in areas of lower transmission.

In areas of high intensity of transmission it remains uncertain whether artificially reducing the rate of natural parasite exposure - through sustained vector 
control or personal protection - will lead to new epidemiological conditions typical of intermediate transmission. It seems likely that the result would be a change in age-specific risks of disease outcomes resulting in a higher mean age of severe disease and death. It is less certain whether there would be an overall change in cumulative disease or risk of death throughout childhood.

A reduction in transmission in areas of high intensity parasite transmission is initially marked by a reduction in disease in all age groups (because a reduced challenge is met with a high level of immunity). This has been shown clearly during short-term studies of insecticide-treated bed nets or indoor residual housespraying in Africa. Thereafter, children born into the population grow up facing the new reduced level of challenge and presumably develop an immune profile and disease experience similar to that of children born in other areas with similar challenge. The net result may be that, over time, the severe disease and, possibly malaria-specific death rates, re-equibrilate to those of the new reduced intensity transmission conditions. Conversely, interventions in areas in which the transmission intensity is already low could provide conditions in which the relationship between parasite exposure, immunity and disease results in a low risk of serious disease. Such ecological conditions represent the fringes of stable transmission and may be subject to epidemics.

A focus on the direct effects of infection upon malariaspecific disease and death provides only part of the overall public health equation and ignores the significance of possible consequences of $P$. falciparum infection. Chronic subclinical infections may render an individual anaemic or predispose to under-nutrition. These processes in themselves may increase susceptibility to severe clinical outcomes of future infection. It has also been argued that subclinical infections influence the severity and outcome of other infectious diseases [14]. There is much evidence that asymptomatic infection of the placenta of a pregnant woman significantly reduces the weight of the child, reducing its survival chances [15]. Patients seek treatment and treatments often carry their own risks of fatal or morbid outcomes. Those who survive the severe pathological consequences of infection may be left with debilitating sequelae, such as spasticity or epilepsy [7, 16]. More subtle consequences, including behavioural disturbances or cognitive impairment, have also been described. A schematic representation of the direct and indirect consequences of $P$. falciparum infection is shown in the Box.

Before the recent 'Roll Back Malaria' initiative [4] the most significant period in the history of malaria control in Africa was the outcome of the conference held by the World Health Organization (WHO) in Kampala, Uganda, in 1950 [17]. Supporters of global eradication were adamant that Africa could achieve the successes achieved by co-ordinated mass action (particularly by use of DDT) in South America, India and some parts of Africa, such as Freetown, Sierra Leone. The 20 years following the Kampala conference witnessed limited success of several small projects in Africa, none of which was sustained. For whatever reason, the guiding principle that the parasite's cycle between man and vector could be broken forever was recognised as impracticable for most of the African continent. The agenda was redefined from parasite eradication to disease control. At this juncture, despite our detailed

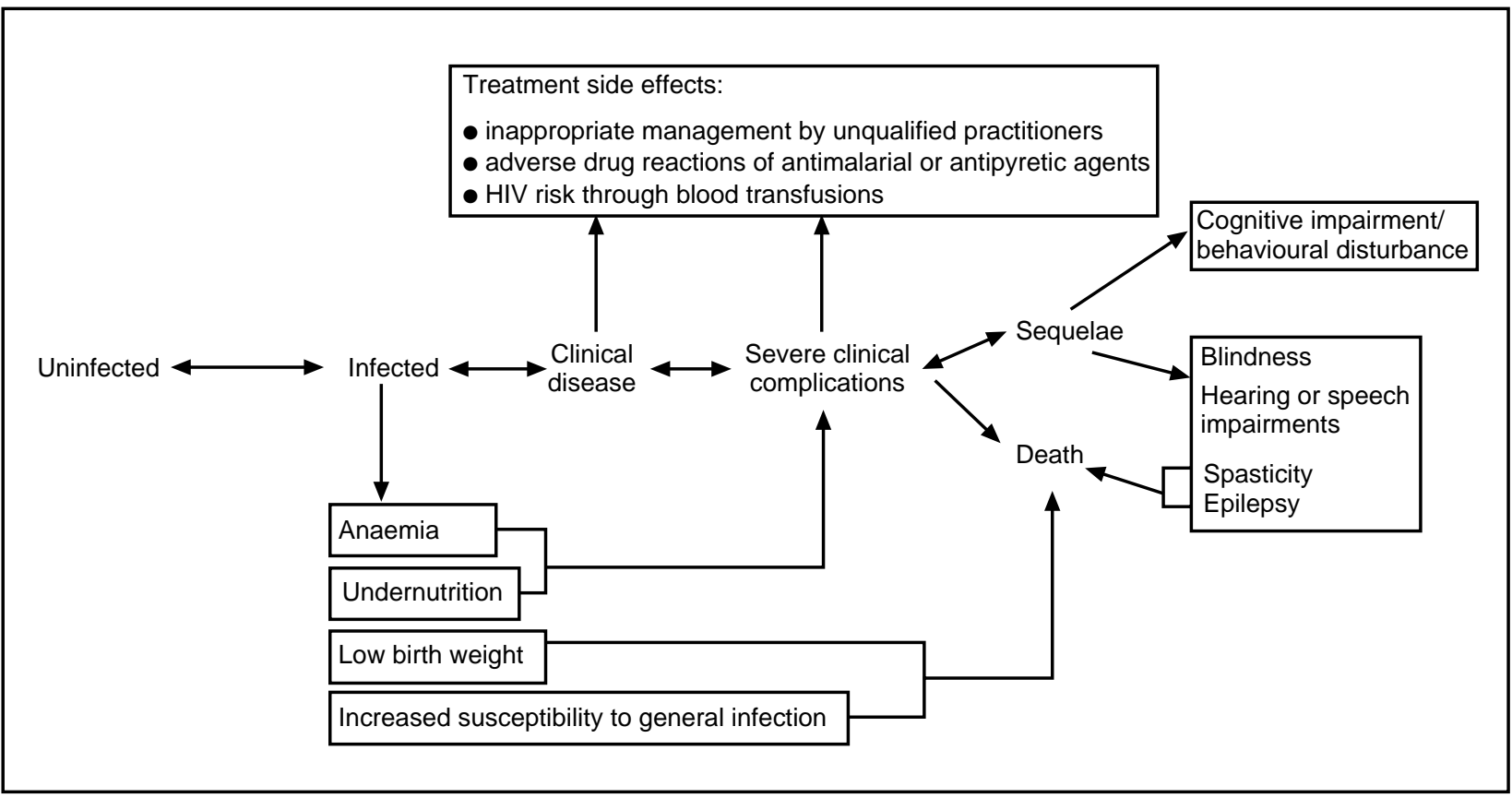

Direct and indirect health consequences of $P$. falciparum infection. 
understanding of the bionomics of infection between primary and secondary hosts, it was not possible to quantify the indirect but severe risks to the human population (see right-hand side of the Box). This has hampered the construction of an epidemiological framework that would allow the effective targeting of cost-effective strategies.

The health impact of $P$. falciparum varies with age, geography and the consequences of various interventions that influence risk. Combining this evidence should provide an informed approach to disease control $[18,19]$. A better understanding of the public health consequences of malaria will help to define costeffective strategies that could be supported by the new wave of international commitment to malaria control in Africa. The most significant challenges facing the malaria epidemiologist at the onset of the new millennium are to define the combined risks of disease, disability and death, and to understand how these risks change from birth through adulthood according to the dependent factors of infection, immunity and control.

R.W.S. is supported by the Wellcome Trust as part of the Senior Fellowships programme in basic biomedical science (\#033340).

ROBERT W. SNOW

Kenya Medical Research Institute/Wellcome Trust Collaborative Programme, P.O. Box 43640, Nairobi, Kenya and Centre for Tropical Medicine, University of Oxford, John Radcliffe Hospital, Headington, Oxford, OX3 9DU (e-mail: bobsnow@wtrl.or.ke)

\section{References}

1. League of Nations. The therapeutics of malaria: Third general report of the Malaria Commission. $Q$ Bull Health Organ League Nations 1933; 2: 181-285.

2. De Meillon B. League of Nations. Malaria under African conditions. II. The control of malaria in South Africa by measures directed against the adult mosquitoes in habitations. Q Bull Health Organ League Nations 1936; 5: 134-137.
3. World Bank. World Development Report 1993: investing in health. New Delhi, Tulika. 1994.

4. World Health Organization. The World Health Report 1999: making a difference. Geneva, World Health Organization. 1999.

5. Gallup JL, Sachs JD. Geography and economic development. Paper presented at the World Bank's annual bank conference on development economics, 20 April, 1998 (http://www.hiid. harvard.edu/research/newnote.htm1\#geogrowth).

6. Goodman CA, Coleman PA, Mills AJ. Cost-effectiveness of malaria control in sub-Saharan Africa. Lancet 1999; 354: 378-385.

7. Snow RW, Craig M, Deichmann U, Marsh K. Estimating mortality, morbidity and disability due to malaria among Africa's non-pregnant population. Bull World Health Organ 1999; 77: 624-640.

8. Trape JF, Quinet MC, Nzingoula $\mathrm{S}$ et al. Malaria and urbanization in Central Africa: the example of Brazaville. Part V: Pernicious attacks and mortality. Trans $R$ Soc Trop Med Hyg 1987; 81 Suppl 2: 34-42.

9. Seboxa T, Snow RW. Epidemiological features of severe paediatric malaria in north western Ethiopia. East Afr Med J 1997; 74: 780-783.

10. Snow RW, Omumbo JA, Lowe B et al. Relation between severe malaria morbidity in children and level of Plasmodium falciparum transmission in Africa. Lancet 1997; 349: 16501654.

11. Aremgaud M, Louvain M, Diop Mar I. Etude portant sur 448 cas de paludisme chez l'Africain de la region dakaroise. Bull Soc Med Afr Noire Lgue Frse 1962; 7: 167-196.

12. Marsh K, Snow RW. Malaria transmission and morbidity. Parassitologia 1999; 41: 241-246.

13. Gernaat HBPE, Dechering WHJC, Voorhoeve HWA. Clinical epidemiology of paediatric disease at Nchelenge, north-east Zambia. Ann Trop Paediatr 1998; 18: 129-138.

14. Alonso PL, Lindsay SW, Armstrong JRM et al. The effect of insecticide-treated bed nets on mortality of Gambian children. Lancet 1991; 337: 1499-1502.

15. Slutsker L, Bloland P, Steketee RW, Wirima JJ, Heymann DL, Breman JG. Infant and second-year mortality in rural Malawi: causes and descriptive epidemiology. Am J Trop Med Hyg 1996; 55 (1 Suppl): 77-81.

16. Newton CRJC, Krishna S. Severe falciparum malaria in children: current understanding of pathophysiology and supportive treatment. Pharmacol Ther 1998; 79: 1-53.

17. World Health Organization. Report on the conference on the eradication of malaria in Equatorial Africa, Kampala. World Health Organization, Geneva. Technical Report Series no. 38, 1951.

18. Snow RW, Marsh K, le Sueur D. The need for maps of transmission intensity to guide malaria control in Africa. Parasitol Today 1996; 12: 455-457.

19. Trape J-F, Rogier C. Combating malaria morbidity and mortality by reducing transmission. Parasitol Today 1996; 12: 236-240. 